\title{
Nivel de conocimiento sobre hitos del desarrollo psicomotor: estudio con madres de niños de 0 a 12 meses que asisten a la Unidad de Salud Familiar Posta Ybycuá del Distrito Capiatá
}

\author{
Bibian Johana Enciso Flecha' ${ }^{1}$ Margarita Beatriz Pereira Maldonado
}

\begin{abstract}
Resumen
Introducción: Los hitos del desarrollo constituyen habilidades que marcan la ruta evolutiva del desarrollo infantil. En la actualidad los procesos y condiciones en que se da el desarrollo infantil adquieren centralidad. La calidad de la de atención y estimulación que reciban los niños, posibilita la instalación de competencias para el futuro desarrollo.
\end{abstract}

Objetivo: De esta manera el presente estudio tuvo como propósito analizar el nivel de conocimiento que poseen las madres sobre los hitos del desarrollo psicomotor de niños de 0 a 12 meses de edad que asisten a la Unidad de Salud Familiar Posta Ybycuá del Distrito de Capiatá para consulta externa, en la especialidad pediátrica durante el mes de agosto del año 2018.

Material y Método: Se utilizó un modelo descriptivo, no experimental. La muestra estuvo compuesta por 40 madres, cuyo promedio de edad fue $28,3 \pm 6,7$ (17-44) años. Así mismo, con relación al número de hijos, el 55\% posee un hijo, $27,5 \%$ cuenta con dos hijos, el $15 \%$ tiene tres hijos y el $2,5 \%$ posee cuatro hijos. De esta manera, respecto al nivel educativo, se observa que el $20 \%$ corresponde al primario, $45 \%$ al secundario y $35 \%$ al universitario. El nivel de conocimiento de las mismas fue medido a través de un cuestionario que evalúa las cuatro áreas del desarrollo, motora, cognitiva, lenguaje y socioemocional. Para la recolección de datos, la técnica utilizada fue la encuesta, para lo cual se elaboró un cuestionario constituido por 24 preguntas cerradas de elección politómica, previamente validado por expertos en el área. Los puntajes obtenidos fueron analizados y categorizados en niveles bajo/medio/alto por cada acierto que obtuvo la madre en las respuestas.

Resultados y Conclusión: Los resultados demuestran que el nivel de conocimiento sobre Hitos del Desarrollo Psicomotor es medio (60\% de las madres) en función al rendimiento general, sin embargo, en relación al conocimiento de las mismas respecto a hitos del desarrollo en las diferentes

\footnotetext{
1. Universidad Iberoamericana. Facultad de Ciencias de la Salud.

Tesina presentada para la obtención de la Licenciatura el Psicomotricidad.

E-mail: biyoenciso@gmail.com
}

DOI: 10.26885/rcei.foro.2018.178 
Nivel de conocimiento sobre hitos del desarrollo psicomotor. Enciso \& Pereira

áreas, se evidencia un nivel de conocimiento predominantemente bajo.

Palabras clave: conocimientos, madres, hitos del desarrollo psicomotor.

\section{RefERENCIAS}

Berruezo, P. (2008). El contenido de la Psicomotricidad. Reflexiones para la delimitación de su ámbito teórico y práctico. Revista Interuniversitaria de Formación del Profesorado, 19-34.

Bottini, P. (2013). Las prácticas y los conceptos del cuerpo: Reflexiones desde la Psicomotricidad. Buenos Aires: Miño y Dávila.

Cal, C. (2008). Psicomotricidad clínica en la infancia: Aportes para un diálogo interdiscipplinario. Montevideo: Psicolibros-Waslala.

Campos, A. (2014). Los aportes de las neurociencias a la atención y educación de la primera infancia. Lima: Cerebrum Ediciones.

Camps, C., García, L., Mila, J., Peceli, M. \& Tomás, I. (2011). El psicomotricista en su cuerpo: De los sensoriomotor a la transformación psíquica. Buenos Aires: Miño y Dávila. 